\title{
Ефектът на интерферона и \\ превантивна или терапевтична ваксина върху \\ рекурентна респираторна папиломатоза
}

\author{
С. Вълчева \\ УМБАЛ „Царица Йоанна-ИСУЛ“ \\ Клиника по УНГ-болести
}

Резюме

Рекурентната респираторна папиломатоза (RRP) се причинява от човешки папиломавирус (HPV) тип 6 и тип 11. Засяга както деца, така и възрастни. В млък брой от случаите заболяването може да бъде много агресивно и да предизвика значителна заболеваемост и евентуално смърт. Хирургичната терапия е първично лечение, но при пациенти с агресивно заболяване се започва допълнителна терапия. Повечето от тези допълнителни мероприятия се концентрират върху имуномодулиране, прекъсване на молекулни сигнални каскади или нарушаване на вирусната репликация, за да се намали тежестта на заболяването.

Наскоро беше разработена превантивна ваксина, но данни за ефективността ѝ реално ще има най-рано след едно десетилетие. Междувременно учените изследват други стратегии за ваксиниране в борбата с HPV.

Ще прегледаме следните терапии, използвани като допълнително лечение на RRP: интерферон и терапевтични или превантивни ваксинации. Но все още остава надеждата за $\mathrm{HPV}$ ваксината и нейния потенциал да предотврати бъдещото разпространение на заболяването.

\section{Abstract}

Recurrent respiratory papillomatosis is caused by the human papillomavirus types (HPV) 6 and 11. It affects both children and adults. In a small number of cases, the disease can be very aggressive causing significant morbidity and possibly death. Surgical therapy is the primary treatment but in patients with aggressive disease, adjunctive therapy is initiated. The majority of these adjuncts center on immunomodulation, disruption of molecular signaling cascades or interruption of viral replication to help decrease the severity of the disease.

Recently, a preventative vaccine has become available but data on its effectiveness will be at least a decade away. In the mean time, researchers are examining other vaccination strategies in the fight against HPV disease.

We will review the following therapies used in the adjunct treatment of RRP: interferon et therapeutic or preventative vaccines. However, there is hope on the horizon with regard to the HPV vaccine and its potential to prevent future transmission of this disease.

\section{Въведение}

Рекурентната респираторна папиломатоза (RRP) се причинява от човешки папиломавирус (HPV) тип 6 и тип 11. Характеризира се с пролиферация на доброкачествени плоскоклетъчни папиломи в респираторно-храносмилателния тракт, най-често в ларинкса. Заболяването се характеризира с многократно рецидивиране след хирургично отстраняване с ограничен ефект от терапията. Засяга както деца, така и възрастни.

В мальк брой от случаите заболяването може да бъде много агресивно и да предизвика значителна заболеваемост и евентуално смърт. При агресивно протичане, което налага множество последователни хирургични интервенции за отстраняване на папиломите в рамките на няколко месеца или дори седмици, остатъчното увреждане на гласа и дишането е почти неизбежно. Хирургичната терапия е първично лечение, но при пациенти с агресивно заболяване се започва допълнителна терапия. Повечето от допълнителните мероприятия се концентрират върху имуномодулиране, прекъсване на молекулни сигнални каскади или нарушаване на вирусната репликация, за да се намали тежестта на заболяването.

Респираторната папиломатоза, асоциирана с инфекция с човешки папиломавирус (HPV), е най-честата доброкачествена ларингеална неоплазма. Възрастта на пациентите при началото на заболяването, типъг $\mathrm{HPV}$, броят на хирургичните интервенции са важни прогностични фактори за хода на заболяването. Лезиите са екзофитни и с много висок процент 
на рецидивиране, компрометират лигавицата на дихателните пътища, най-вече на ларинкса. Ювенилната ларингеална папиломатоза е сравнително рядко състояние. В случаи на бързо рецидивиране постоянните увреждания на гласа и дишането са почти неизбежни поради честата нужда от хирургични интервенции за намаляване на обема на обструктиращата маса. Рекурентната ларингеална папиломатоза е хронично заболяване, асоциирано с HPV, което изисква серии от хирургични интервенции за намаляване на обема на папиломите, които водят в дългосрочен план до отслабваща дисфония, ларингеални цикатрикси и по-рядко до малигнена дегенерация.

\section{Диагностика}

В началото на заболяването е трудно да се прецени клиничният ход, а биологичните медиатори на пролиферацията не са добре проучени. Документацията на пациентите се преглежда за демографска информация, възраст по време на поставяне на диагнозата, приблизителна честота на хирургичните интервенции и абсолютен брой на извършените хирургични процедури. Извършва се типизиране на HPV. Прави се експресионен анализ на кодираните от HPV E6 и E7 онкогени с помощта на PCR с обратна транскриптаза.

\section{Адювантна терапия}

Критериите за включване на адювантна терапия са повече от 4 хирургични интервенции годишно, бързо нарастване с обструкция на дихателните пътища.

Алфа-интерферонът е най-широко прилаганият препарат за адювантна терапия на ларингеалната папиломатоза. Интерферонът потиска синтеза на вирусните протеини, има доказано цитостатично и цитокинетично действие. Интерфероните са мощни активатори на NK-клетките и макрофагите. Много автори съобщават за намаление размера на папиломите при лечение с интерферон. Незадоволителен ефект може да има при недостатъчна дозировка и продължителност на лечението. Правени са проучвания за връзката между резултатите от интерфероновото лечение и типа на HPV, изолиран от папиломите. Пациенти с HPV - 11 показват по-слаб резултат от лечението с интерферон (14\%), отколкото тези с HPV - 6 (64\%). Страничните ефекти при лечението с алфа-интерферон се разделят на две категории. Остри реакции, повишена температура, грипоподобни симптоми, втрисане, миалгия и главоболие. Хронични реакции и повишено ниво на трансаминазите, гастроинтестинални оплаквания, левкопения и тромбоцитопения. Може да има още обриви, сърбеж и алопеция. Въпреки наличието на странични явления те много рядко стават причина за прекъсване на лечението с интерферон. Сега се препоръчват имунната стимулация с интерферон алфа по схема. Инжекциите се прилагат подкожно или мускулно в доза от 3 милиона единици. Първия месец - три пъти седмично, втория месец - един път седмично.

Тази схема на лечение се прилага два пъти годишно. При много агресивни форми се прилага три пъти годишно, а при единични случаи - през месец.

Наскоро разработената тетравалентна HPV ваксина индуцира производството на неутрализиращи антитела срещу капсидните антигени на HPV типове 6, 11, 16 и 18, които са асоциирани с респираторната папиломатоза.

Вече се доказа, че ваксината е безопасна и силно имуногенна. Тя може ефективно да предотврати нови инфекции с който и да е от четирите ваксинални типа, а също и индуцираните от тях епителни лезии. Ваксината, обаче, няма никакъв ефект върху вече съществуващи инфекции или лезии. Тук бихме желали да изкажем хипотезата, че ваксинирането срещу HPV би могло да има терапевтичен ефект при RRP чрез предотвратяване на формиране на нови папиломи на допълнителни места. Първите случаи на ваксиниране при RRP, възникнала в младежка възраст, а също и при възрастни индивиди, вече са докладвани и техните серологични резултати се представени. Първичният ваксинационен курс се състои от 3 отделни дози по 0.5 мл, прилагани по схема 0, 2, 6 месеца. След третата имунизация заболяването се стабилизира. Не бяха необходими повече хирургични интервенции за следващите дванайсет месеца. Рискът от това допълнително лечение е нисък.

Смятаме, че си заслужава да се започне мултицентрично изследване, за да се докаже ползата от това лечение, дори ако не се постига пълно елиминиране на вируса. 


\section{Заключение}

През последните няколко години се появиха няколко нови терапевтични възможности, а също и няколко изследвания с практическо значение в областта на болестния процес, които могат да предложат ново виждане и методи за справяне с това заболяване. В България за 1 година над 1000 жени се разболяват, 8 от всички 10 жени се заразяват с човешки папиломен вирус през живота си. Приблизително 1 от 10 души по света (общо над 630 милиона) е заразен с човешки папиломен вирус.

Справянето с RRP напредва. Скорошното лицензиране на профилактичната HPV ваксина е найинтересният напредък. Ниската честота на RRP представя сериозни проблеми при набирането на достатъчен брой пациенти, за да се постигне статистическа значимост.
Въпреки няколкото нови обсъдени по-горе терапии, все още това е заболяване с потенциал за висока смъртност. Тъй като фокусът на терапията се измества от лечението към превенцията, ще отнеме доста години да се определи дали стратегията с превенция е ефективна за ограничаване на разпространението на това заболяване.

Междувременно са необходими още изследвания, за да се установи по-добър контрол върху този болестен процес. Рентабилността на HPV ваксината зависи от продължителността на индуцирания от ваксината имунитет и се подобрява с постигане на добро покритие на момичетата в предпубертетна възраст и към жени от 18 до 46 години. Преразглеждане на практиките за скрининг. Младите жени, по-време на пубертета и в млада възраст, са най-уязвими към човешкия папиломен вирус.

\section{Литература:}

1 Alberts DS, Coulthard SW, Meyskens FL. Regression of aggressive laryngeal papillomatosis with 13 - cis - retinoic acid. J Boil Response Mod 1986; 5: 124-8

2 Arndt O, Johannes A, Zeise K, Brock J. High - risk HPV types in oral and laryngeal papilloma and leukoplakia. Laryngorhinootology 1997; 76: $142-149$

3 Avidano MA, Singleton GT. Adjuvant drug strategies in the treatment of recurrent respiratory papillomatosis. Otolaryngol Head Neck Surg 1995; 112: 187-202

4 Benjamin BN, Gatenby PA, Kitchen R, Harrison H, Cameron K, Basten A. Alpha - interferon (Wellferon) as an adjunct to standard surgical therapy in the management of recurrent respiratory papillomatosis. Ann Otol Rhinol Laryngol 1988; 87: 370-80

5 Bishai D, Kashima H, Shah K. The cost of juvenile - onset recurrent respiratory papillomatosis. Arch Otolaryngol Head Neck Surg 2000; 126: 935-9

6 Boston M, Derkay CS. Recurrent respiratory papillomatosis. Clin Pulm Med 2003; 10: 10-16

7 Bothwell M. Human papilloma virus papilloma. Otolaryngol Head Neck Surg 2005; 133: 308-9

8 Chireshkin DG, Kuznetsov VP, Onufreva EK, Pritsker AD. Effectivenes of human leucocytiv interferon with papillomatosis of the larynx, trachea and bronchi. Vestn Otorhinolar 1991; 5: 19-21

9 Dickens P, Srivastava G, Loke SL, Larkin S. Human papilloma virus 6, 11 and 16 in laryngeal papillomas. J Pathol 1991; 165: 243-246

10 Doyle DJ, Henderson LA, LeJeune FE, Miller RH. Changes in human papillomavirus typing of recurrent respiratory papillomatosis progressing to malignant neoplasm. Arch otolaryngol Head Neck Sug 1994; 120: 1273-6

11 Gerein V, lodemann E, Bell G, vonIlberg C, Kornhuber B. Results of long - term leucocyte interferon (alpha IFN) therapy using an individually determined dose schedule in recurrent laryngeal papillomatosis. Klin Pediatr 1987; 199: 224-9

12 Gereom V, Rastprguev E, Gerein J, Jecker P, Pfister H. Use of interferon - alpha in recurrent respiratory papillomatosis: 20-year foolow - up. Ann Otol Rhinol Laryngol 2005; 114:463-71

13 Haglund S, Lindquist P, Cantell K, Strander H. Interferon therapy in juvenile laryngeal papillomatosis Arch Otolaryngol 1981; 107: 327-32

14 Healy GB, Gelber RD, Trowbridge AL, et al. Treatment of recurrent respiratory papillomatosis with human leucocyte interferon. Results of a multicenter randomized clinical trial N Engl J Med 1988; 319: 401-7.

15 Kashima H, Leventhal B, Clark K, Cohen S, Dedo H, Donovan D, Fearon B, Gardiner L, Goepfert H, Lusk R. Interferon - alpha - N1 (Wellferon) in juvenile - onset recurrent respiratory papillomatosis: resuts of a randomized study in twelve collaborative institutions. Laryngoscope 1988; 98: 334-40

16 Koltson VD, Chireshkin DG, Onufrieva EK, Nurmukhametov RK, Malinovskaia VV, Ershov FI. Assessment of the formation of antibodies to interferon in patients with juvenile respiratory papillomatosis on interferon therapy. Vestn Otorhinolaryngol 1996; 7: 25-7

17 Leventhal BG, Kashima HK, Mounts P, Thurmond L, Chapman S, Buckley S, Wold D. Long - term response of recurrent respiratory papollomatosis to treatment with lymphblastoid interferon alfa - n1. Papilloma study group. N Engl J Med 1991; 325: 613 -7 Lusk RP, McCabe BF, Mixon JH. Three - year experience of trating recurrent respiratory papilloma with interferon. Ann Otol Rhinol Laryngol 1987; 96: 158-62

18 Leventhal Bg, Kashima HK, Weck PW, Mounts P, Whisnant JK, Clark KL, Cohen S, Dedo HH, Donovan DJ, Fearon BW. Randomized surgical adjuvant trial of interferon alfa $\mathrm{n}-1$ in recurrent papillomatosis. Arch Otolaryngol Head Neck Surg 1988; 114: 1163-9.

19 Mullooly VM, Abramson AL, Steinberg BM, Horowitz MS. Clinical effects of alpha - interferon dose variation on laryngeal papilloma. Laryngoscope 1988; 98: 1324-29

20 Nigel R, Pashley MB. Can mumps vaccine induce remission in recurrent respiratory papilloma? Arch Otolaryngol Head Neck Surg 2002; 783-6.

21 Pritsker AD, Grigorian SS, Onufrieva SS, Chireshkin DG, Ershov FI. The interferon status and circulating immunoglobulins during the interferon therapy of respiratory papillomatosis. Vopr Virusol 1991; 36: 411-4

22 Strome M. Analysis of an autogenuos vaccine in the treatment of juvenile papillomatosis of the larynx. Laryngoscope 1969; 79: $272-9$

23 Thurmond LM, Brand CM, Leventhal BG, Finter NB, Johnston JM. Antibodies in patients with recurrent respiratory papillomatosis treated with lymphoblastoid interferon. J Lab Clin Med 1991; 118: 232-40

24 Zenner HP, Kley W, Claros B, Lahas Z, Lobe LP, Pavelka R, Plath P, Ribari O, Xiethammer D, Hirche H. Recombinant Interferon - alpha $-2 \mathrm{c}$ in laryngeal papillomatosis: preliminary results of a preospective multicentre trial. Oncology 1985; Suppl 1; 42: 15-18 